\title{
A Study on the Level of High-Quality Development in Tibet Based on the Satisfaction of Government Quality Work
}

\author{
Liu Siyue ${ }^{1}$ \\ ${ }^{1}$ Government Management Innovation Standardization Institute, China National Institute of Standardization (CNIS), Beijing, China
}

\begin{abstract}
This paper explores the level of high-quality economic development in the Tibet Autonomous Region in 2019 by using the quantitative method and taking the public satisfaction of government quality work as the path. The article holds that the Tibet Autonomous Region's economy is developing at a high speed, but the level of high-quality economic development is still at a relatively satisfactory level and there is still much room for improvement. Generally speaking, the level of environmental quality satisfaction is higher, followed by the level of service quality, engineering quality and product quality satisfaction, and the level of quality consciousness satisfaction is lower. In addition to the structural factors such as backward production capacity, the micro-factors such as product qualification rate and engineering safety have a great influence on the high-quality development of Tibet.
\end{abstract}

\section{INTRODUCTION}

Since the 18th National Congress, China has made remarkable achievements in economic development. The 19th National Congress declared that China's economic development has moved from a high-speed development stage to a high-quality development stage, endowing China's economy with a different connotation from the past. In Jin Pei's opinion, quality refers to the use value characteristic that the product can satisfy meet the actual needs. In competitive domain, it also refers to the quality acceptability and competitiveness with higher cost performance and thus more effective to meet the needs. And high-quality development is an economic development mode, structure and dynamic state that can better meet the growing needs of the people ${ }^{[1]}$. At present, China is faced with the dilemma of eliminating backward production capacity and reforming supply-side structure. Therefore, we must realize that China's economy is still developing unevenly and inadequately, and its development quality and efficiency are not high.

The Tibet Autonomous Region, as one of the fastest-growing provinces in China, has maintained double-digit economic growth for years. After years of rapid development, what is the quality of Tibet's economic development? For this point, the existing academic research is rarely involved. Taking the government quality work of the Tibet Autonomous Region in 2019 as a breakthrough point, this paper probes into the quality development of the Tibet Autonomous Region by analyzing the social public satisfaction level of the government quality work in the region and its influencing factors, and provides some reference for the academic research and the development of high quality in Tibet.

\section{INDEX SYSTEM}

In measuring the quality work of the Tibet Autonomous Region Government in 2019, this paper selects the five areas of product quality, engineering quality, service quality, environmental quality and quality consciousness as the first-level indexes, and further refines them into the second-level indexes and evaluation indexes that are easily felt by the residents and closely related to daily life. The index system and measurement methods are shown in Table 1 .

${ }^{[1]}$ Jin Pei. Study on "High-Quality Development" Economics [J]. China Industrial Economics, No. 4, 2018, pp. 5-18.

$\overline{\text { liusy@cnis.ac.cn }}$ 
Table 1 Social Public Evaluation Contents of Quality Work of the Tibet Autonomous Region Government

\begin{tabular}{|c|c|c|c|}
\hline First-level index & Second-level index & Measurement index & \multirow{28}{*}{$\begin{array}{l}\text { Very unsatisfied } \mathrm{i}=1 ; \\
\text { Unsatisfied } \mathrm{i}=2 \\
\text { So-so } \mathrm{i}=3 ; \\
\text { Satisfied } \mathrm{i}=4 \\
\text { Very satisfied } \mathrm{i}=5\end{array}$} \\
\hline \multirow{6}{*}{ Product quality } & \multirow{2}{*}{ Food and drug quality } & Medicines & \\
\hline & & Food & \\
\hline & Quality of agricultural products & $\begin{array}{l}\text { Food, vegetables, fruit, meat, aquatic } \\
\text { products }\end{array}$ & \\
\hline & & Durable consumer goods & \\
\hline & Quality of consumer goods & Daily necessities & \\
\hline & Quality of special equipment & $\begin{array}{l}\text { Public facilities in elevators and } \\
\text { playgrounds }\end{array}$ & \\
\hline \multirow{2}{*}{ Engineering quality } & $\begin{array}{l}\text { Construction engineering } \\
\text { quality }\end{array}$ & House & \\
\hline & Traffic engineering quality & Public transport engineering & \\
\hline \multirow{14}{*}{ Service quality } & \multirow{7}{*}{ Productive service quality } & Short-distance public transport & \\
\hline & & Long-distance public transport & \\
\hline & & Communications and Network Services & \\
\hline & & Banking service & \\
\hline & & Insurance service & \\
\hline & & E-commerce service & \\
\hline & & Logistics and Express Service & \\
\hline & \multirow{7}{*}{ Living service quality } & Educational service & \\
\hline & & Medical service & \\
\hline & & Service for the aged & \\
\hline & & Public-utility service & \\
\hline & & Tourism service & \\
\hline & & Public cultural service & \\
\hline & & Home decoration service & \\
\hline \multirow{2}{*}{ Environmental quality } & Water environmental quality & River and lake water quality & \\
\hline & Atmospheric quality & Air & \\
\hline \multirow{3}{*}{ Quality consciousness } & Quality complaint & Quality Complaint Satisfaction & \\
\hline & $\begin{array}{l}\text { Information disclosure and } \\
\text { advocacy }\end{array}$ & $\begin{array}{l}\text { Quality Concern, Quality Safety Issues } \\
\text { Announcement, Quality Publicity }\end{array}$ & \\
\hline & Quality improvement & $\begin{array}{l}\text { Improvement of Product, Engineering, } \\
\text { Environment and Service Quality }\end{array}$ & \\
\hline
\end{tabular}

\section{CACULATION METHOD}

The calculation methods for various levels of indexes are as follows:

Measurement index $A_{m}=\sum_{t=1}^{\mathrm{T}} m_{t} \div T \times 20$;

Second-level index $B_{i j}=\sum_{k=1}^{n_{i j}} r_{i j k} \times A_{m}$;

First-level index $C_{i}=\sum_{j=1}^{n_{i}} q_{i j} \times B_{i j}$;

Total score $D=\sum_{i=1}^{5} p_{i} \times C_{i}$.

Among them, $A_{m}$ represents the m-th measurement index, $T$ represents the sample size, $B_{i j}$ represents the $j$-th second-level index under the $\mathrm{i}$-th first-level index, and $\mathrm{k}$ represents the number of measurement indexes under the $\mathrm{j}$-th second-level index under the $\mathrm{i}$-th first-level index, $\mathrm{C}_{\mathrm{i}}$ represents the $\mathrm{i}$-th first-level index, $\mathrm{j}$ represents the number of second-level indexes under the $\mathrm{i}$-th first-level index, and $\mathrm{D}$ represents the total score. $\mathrm{r}_{\mathrm{ijk}}, \mathrm{q}_{\mathrm{ij}}$, and $\mathrm{p}_{\mathrm{i}}$ are the second-level and first-level indexes and the total score weight, respectively, determined by experts.

\section{SURVEY SAMPLES}

According to the principle of probability scale proportion and stratified sampling, the survey covers seven cities in the Tibet Autonomous Region, with 1,817 valid samples collected. The sample size and its distribution are shown in Table 2 as follows:

Table 2 Distribution condition of survey sample size

\begin{tabular}{|c|c|c|}
\hline $\begin{array}{c}\text { The city to } \\
\text { which it } \\
\text { belongs }\end{array}$ & $\begin{array}{c}\text { Count of the city to which } \\
\text { it belongs }\end{array}$ & $\begin{array}{c}\text { GT of the city's } \\
\text { count }\end{array}$ \\
\hline Lhasa & 399 & $21.96 \%$ \\
\hline Shannan & 318 & $17.50 \%$ \\
\hline Chang Du & 303 & $16.68 \%$ \\
\hline Naqu & 303 & $16.68 \%$ \\
\hline Shigatse & 212 & $11.67 \%$ \\
\hline Ngari & 197 & $10.84 \%$ \\
\hline Lin Zhi & 85 & $4.68 \%$ \\
\hline
\end{tabular}

\section{SURVEY RESULTS}

\subsection{General situation}

In 2019, the public satisfaction evaluation of the government quality work of the Tibet Autonomous Region is given an overall score of 67.59 , which is at a relatively satisfactory level. Among them, the environmental score is the highest (68.75 points); the 
service quality, engineering quality and product quality are the second (68.24 points, 67.37 points and 67.14 points respectively); the quality consciousness score is the lowest (66.45 points), as shown in Figure 1, Figure 2.

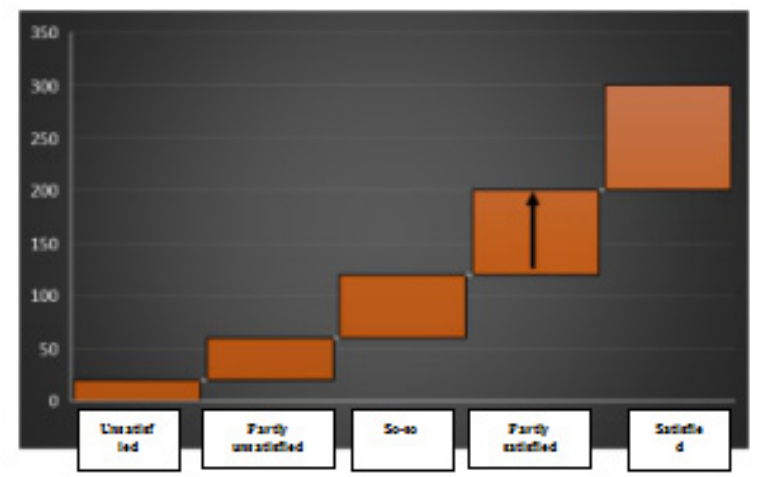

Figure 1 Social Public Satisfaction Level of Tibet Government Quality Work in 2019

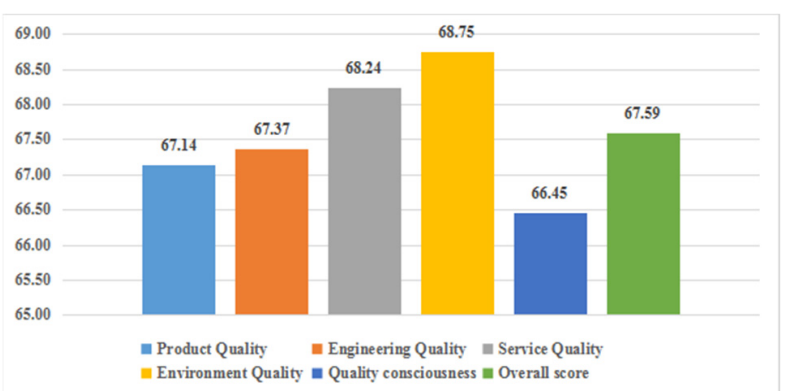

Figure 2 Social Public Satisfaction Score of Tibetan Government Quality Work in 2019

\subsection{Status of sub-item indexes}

Under the first-level index of product quality, the quality satisfaction of grain, vegetable, melon and fruit, meat and aquatic products have the highest score of 69.61 , while that of drug quality have the lowest score of 63.95. Under the first-level index of project quality, the quality satisfaction evaluation of public transportation project is higher, and the score is 67.42 , while that of house quality is lower, and the score is 67.32. Under the first-level index of service quality, the satisfaction rating of tourism service quality is higher, with the score of 68.64 , while the satisfaction rating of short-distance public transport service is lower, with the score of 67.89. Under the first-level index of environmental quality, the river lake water quality satisfaction evaluation is higher, with the score of 68.88 , and the air quality satisfaction evaluation is lower, with the score of 68.64. Under the first-level index of quality consciousness, the product quality improvement satisfaction rating is the highest, with the score of 68.49 , while the quality complaint satisfaction rating is lower, with the score of 63.57 .

\subsection{Regional Analysis}

In 2019, the social public satisfaction score of quality work in all the cities of Tibet Autonomous Region shows the trend of "high in the middle and low in both sides". The cities of Shannan, Lhasa and Naqu rank in the top three, and the scores of satisfaction evaluation are 69.24, 68.72 and 67.70 respectively. The cities of Shigatse, Ngari and Chang Du rank in the fourth to sixth place, and the scores of satisfaction evaluation are 67.64, 66.31 and 65.88 respectively. The satisfaction evaluation of Lin Zhi was lower, ranking the last in the province, with a satisfaction score of 64.69, as shown in Figure 3.

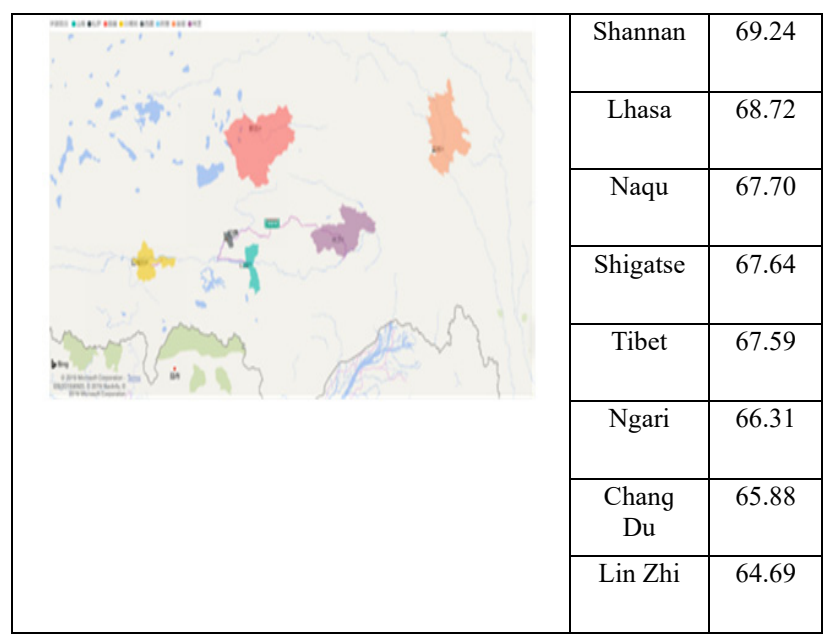

Figure 3 Score in each region

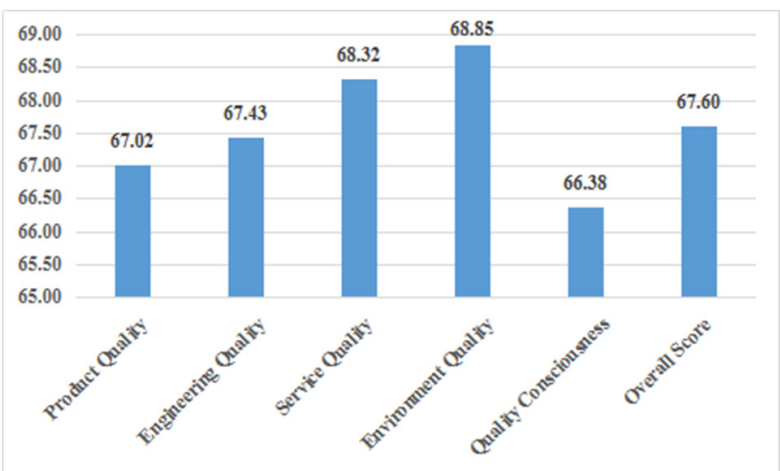

Figure 4 Score of Satisfaction Evaluation in Central Tibet Economic Zone 


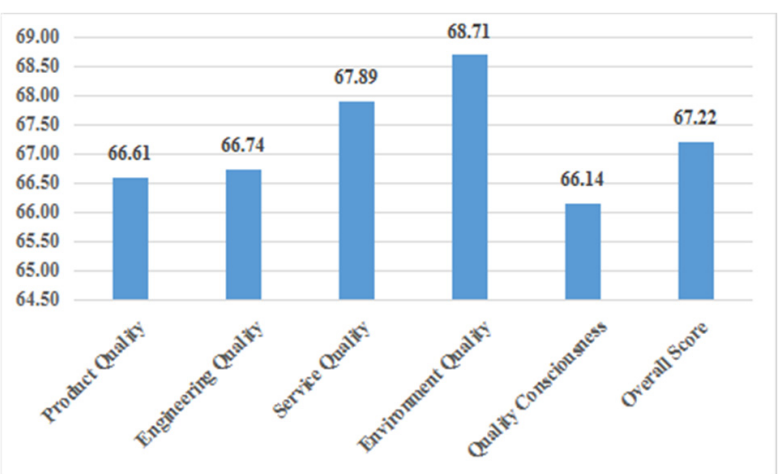

Figure 5 Score of Satisfaction Evaluation in Western Tibet Economic Zone

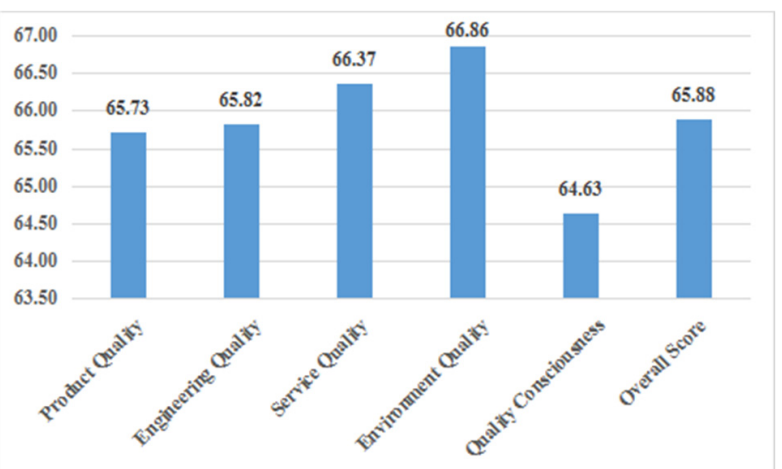

Figure 6 Score of Satisfaction Evaluation in Eastern Tibet Economic Zone

As shown in Figure 4 to 6 , the performance of satisfaction in the central economic zone mainly composed of Shannan, Lhasa, central and Eastern Naqu, Shigatse and Lin Zhi, the western economic zone composed of Ngari, Western Naqu and Western Rikazi, and the eastern economic zone composed of Chang Du show strong similarity, in which the environmental quality is the highest in all three regions, followed by the service quality, engineering quality and product instructions, and the quality consciousness in the three regions is the lowest. In addition, the overall satisfaction score of the central economic zone is the highest at 67.60 , followed by that of the western economic zone at 67.22 and that of the eastern economic zone at 65.88 .

\section{PROBLEMS}

There is a strong correlation between government performance and social public satisfaction. Research shows that a variety of factors related to government performance can influence the level of public satisfaction. The micro-factors such as personal security, the impact of policy on personal economy, crime and so on, have more significant influence on the level of satisfaction than the macro-factors such as economic benefit and national policy evaluation ${ }^{[2]}$. Therefore, the government should invest more capital in the field of public service. The online public opinion data obtained in this paper show that the micro-level factors, such as product qualification rate, quality complaints and the completeness of public facilities, play an important role in the social public satisfaction level of the Tibetan government quality work.

\subsection{Quality Complaint Satisfaction}

In recent years, Tibet has taken active measures to issue a number of notices on quality improvement, focusing on reporting complaints about product quality and engineering quality. As a relatively weak project quality in the Tibet Autonomous Region, the improvement in recent years has been slow, and at the same time, there are serious safety hidden dangers, which have not been paid enough attention by the relevant departments, and the government has not responded promptly and effectively to the complaints of the people ${ }^{[3]}$.

\subsection{Drug Quality}

In 2019, the Tibet Autonomous Region Institute for Food and Drug Control found that a drug company in Hunan Province had detected the relevant substance, which was not in conformity with the regulations ${ }^{[4]}$; and the China Institute for Food and Drug Control detected a certain character in the fermented bean of a urogenital hospital in Lhasa, and the relevant departments decided that the drug was not in conformity with the regulations ${ }^{[5]}$. In another previous drug test before this, Anhui Institute for Food and Drug Control detected that the betel nut of a hospital in Lin Zhi contained aflatoxin, so the relevant departments decided that the drug did not comply with the regulations; Henan Provincial Institute for Food and Drug Control detected micro characteristics and extracts

${ }^{[2]}$ Paul Whiteley, Harold D. Clarke, David Sanders, Marianne C. Stewart. Government Performance and Life Satisfaction in Contemporary Britain[J]. The Journal of Politics, Vol. 72, No. 3, July 2010, pp. 733746.

${ }^{3]}$ Jiang Jie. Serious quality problems have been exposed in Tibet Lhasa-Shigatse Railway, and the project headquarters are suspected to cover up and connive (EB/OL). http://dy.163.com/v2/article/detail/CRT4JM2H0512CLHG.html , 8-15-2017.

Lhasa, Tibet: Stick to the bottom line of quality safety and strengthen the safety supervision of special equipment [EB/OL]. https://cj.sina.com.cn/articles/view/3037284894/b5094a1e02000o26m?f rom=finance, $10-31-2019$.

${ }^{[4]}$ The sample test of ethylpiperisone hydrochloride tablets produced by Hunan Yada Pharmaceutical Co., Ltd. was not qualified [EB/OL]. http://www.cqn.com.cn/ms/content/11/27/2019/content_7831385.htm, 11-27-2019.

${ }^{[5]}$ National Medical Products Administration: 57 batches of drugs do not comply $[\mathrm{EB} / \mathrm{OL}]$

http://www.cqn.com.cn/ms/content/11/26/2019/content_7826972.htm, 11-26-2019. 
in yam of a hospital in Lin Zhi, and the relevant departments also decided that the drug did not comply with the regulations ${ }^{[6]}$. These cases further confirm the results of the survey on the low quality of drugs in the Tibet Autonomous Region.

\subsection{Public facilities in Elevator and Playground}

The overall level of public facilities in the Tibet Autonomous Region is relatively low, and there are still many regional public facilities bottlenecks that have not been solved, including the construction of urban public transport, the construction of charging piles, the construction of public toilet facilities and the construction of fitness facilities. These areas require the strong assistance and support of foreign aid teams ${ }^{[7]}$. These phenomena have weakened the overall level of public facilities quality in Tibet Autonomous Region.

\subsection{Food}

In the food safety inspection of 665 batches of samples of six major foodstuffs, such as starch products, edible agricultural products, meat products, biscuits, fruit products and special dietary foods, organized by the State Administration for Market Regulation recently, it was found that the red shrimp sold by a company in Chang Du, Tibet Autonomous Region contained chloramphenicol and other substances that did not conform to the national food safety standards. The deep-sea yellow croaker sold by a company dealing in aquatic products in Lhasa, Tibet Autonomous Region contained substances that do not conform to the national standards for food safety, such as Enrofloxacin. These products are thus declared to be substandard products ${ }^{[8]}$.

\subsection{House Quality}

The problems existing in the house quality of Tibet Autonomous Region should be paid attention to by the government. First, there are large structural differences and imbalances in housing between cities, towns and townships; secondly, compared with the rest of the

\footnotetext{
${ }^{[6]}$ National Medical Products Administration: 20 batches of drugs produced by 19 enterprises do not conform to the regulations [EB/OL]. http://www.cqn.com.cn/ms/content/04/20-2019/content_7028949.htm, 4-20-2019.

Lu Jinfu. The Fujian Aid to Tibet team has improved the public facilities in Changdu, Tibet, so that the Tibetans have a "sense of gain" [EB/OL].

http://www.tibet.cn/cn/aid_tibet/news/201907/t20190717_6638935.html, 7-17-2019.

8] Circular of the General Administration of State Administration for Market Regulation on the Disqualification of 10 Batches of Food [31 of 2019] http://gkml.samr.gov.cn/nsjg/spcjs/201909/t20190909 306673.html, 9-9-2019.
}

country, housing in the Tibet Autonomous Region is still at a low level and there is a lot of room for improvement; thirdly, the housing price keeps rising, which increases residents' spending on buying and renting houses and affects the quality of life of the people ${ }^{[9]}$.

\section{SUGGESTIONS}

In order to get a better understanding of the quality work of the government of Tibet Autonomous Region and the people's suggestions on the quality work of the government, this paper uses text mining and Chinese word segmentation technology to deal with the proposed text of the questionnaire in full mode, and finally establishes the word cloud map with the result of word frequency statistics.

"No" is the most frequently used word in people's opinions and suggestions, indicating that more people are satisfied with the overall situation of the government's quality work in the Tibet Autonomous Region. At the same time, there are still many people who say that the government should strengthen and improve the quality of work, solve problems arising from local quality work and improve the people's living standards. People believe that education, medicine, health, medical care, quality concern, pollution, public service, service attitude, public facilities, poverty alleviation and other areas should be the government's primary concern.

The research shows that it is necessary to construct a brand-new economic system to realize high-quality development, which is characterized by innovation-oriented industrial structure, coordinated development mode between urban and rural areas, socialist market economy system and persistent power of all-round opening of market ${ }^{[10]}$. In addition, the government and the market are the main drivers of high-quality economic development. We should continuously improve the efficiency of the government, release the vitality of the market and promote the coordinated operation of high-quality economic development [11]. These principles should also be followed for the high-quality development of Tibet. According to the evaluation results of the quality work satisfaction of the government of Tibet Autonomous Region, the following suggestions for improving the quality work of the government are put forward:

\footnotetext{
Yang Chengzhou, Yang Fan. Analysis of Housing Changes in Contemporary Tibetan Families-Based on Census Data [J]. China Tibetology (Beijing) No. 4, 2018, pp. 103-114.

${ }^{[10]}$ Quan Heng. Navigating China's Economic Development in the New Era From High-Speed to High-Quality Growth[J]. China Quarterly of International Strategic Studies, Vol. 4, No. 2, pp177-192.

${ }^{[11]}$ Zheng Shangzhi, Zhao Xue. Who can promote the development of high quality: the government or the efficient market?-Empirical Test Based on Panel Threshold Model [J]. Contemporary Economic Management, Vol. 42, 2020.
} 
(1) Do a good job in top-level design and strive for policy support of the Central Committee

Tibet's high-quality development should be guided by the overall concept of development. The results of the quality evaluation show that the satisfaction evaluation scores of environmental quality and service quality in Tibet Autonomous Region are all good. In addition, the three economic zones in the central, western and eastern parts of the Tibet Autonomous Region cooperate with each other in quality work, give play to their respective advantages, form a cooperation mechanism to jointly promote the coordinated development of quality work in Tibet and lay a sound economic foundation for the high-quality development of Tibet. Because of the special geographical environment, the overall level of quality work in Tibet is lower, and it is necessary to further obtain the support of the Central Committee in policy and improve the overall level of quality work. Quality complaint satisfaction, medicines, elevators and playground public facilities, food and house quality are Tibet's short boards. Therefore, the government should actively strive for the support of the central government in these areas, further improve the business environment, attract foreign investment, and strive to improve the overall situation of quality work in Tibet.

(2) Strengthen the construction of infrastructure facilities and continue to promote the construction of major projects

The Sichuan-Tibet Railway and other major projects are major projects involving the economic and social development and improvement of the people's livelihood of Tibet, and have made outstanding contributions to the high-quality development of Tibet. We will further accelerate the construction of these major projects and enhance the capacity of infrastructure to support high-quality development. The results of the work quality monitoring by the government of the Tibet Autonomous Region in 2019 show that the quality of products, projects, services and environmental quality in different cities and regions lags behind that of other regions, and the quality difference between urban and rural areas has not been effectively reduced. In order to make up for these differences and bridge the development gap between the regions, the government should strive for the support of the national ministries and commissions for the construction of major projects in Tibet, spread the infrastructure to all parts of Tibet, promote the market vitality of Tibet, and constantly promote the great leap forward in the quality work of the government in all fields.

\section{ACKNOWLEDGMENT}

I would like to appreciate my colleagues, Feng Lei, Huang Juxiu, Liao Jingxing and Sun Ni for their useful help when I wrote this article. I would also like to thank the data execution company for collecting this huge amount of data for me to analyze. Without their help, I cannot complete this article.

\section{REFERENCES}

1. Jin Pei. Study on the "High Quality Development" Economics [J]. China Industrial Economics, No. 4, 2018, pp. 5-18.

2. Whiteley, P., Harold D. Clarke, David Sanders, Marianne C. Stewart. Government Performance and Life Satisfaction in Contemporary Britain[J]. The Journal of Politics, Vol. 72, No. 3, July 2010, pp. 733-746.

3. Jiang Jie. Serious quality problems have been exposed in Tibet Lhasa-Shigatse Railway, and the project headquarters are suspected to cover up and connive (EB/OL).

http://dy.163.com/v2/article/detail/CRT4JM2H0512C LHG.html, 8-15-2017.

4. Lhasa, Tibet: Stick to the bottom line of quality safety and strengthen the safety supervision of special equipment $[\mathrm{EB} / \mathrm{OL}]$.

https://cj.sina.com.cn/articles/view/3037284894/b509 4a1e02000o26m?from=finance, 10-31-2019.

5. Yang Chengzhou, Yang Fan. Analysis of Housing Changes in Contemporary Tibetan Families-Based on Census Data [J]. China Tibetology (Beijing) No. 4, 2018, pp. 103-114.

6. Heng, Quan. Navigating China's Economic Development in the New Era From High-Speed to High-Quality Growth[J]. China Quarterly of International Strategic Studies, Vol. 4, No. 2, pp177-192.

7. Zheng Shangzhi, Zhao Xue. Who can promote the development of high quality: the government or the efficient market?-Empirical Test Based on Panel Threshold Model [J]. Contemporary Economic Management, Vol. 42, 2020.

8. McGill, Ronald. Institutional Development: A Third World City Management Perspective[M]. London: St Martin's Press, 1997.

9. Casella, G., Roger L. Berger. Statistical Inference (2nd ed.)[M]. Pacific Grove: Duxbury Press, 2002.

10. Freedman, David. Statistical Models: Theory and Practice (revised ed.)[M]. New York: Cambridge University Press, 2009.

11. Shi Qingjun. Government Performance Evaluation: Concepts, Methods and Applications of Evaluation Results [M]. Beijing: Peking University Press, 2016.

12. Jake VanderPlas [US]. Python Data Science Handbook [M]. Beijing: Posts and Telecom Press, 2018. 